\title{
Device Age
}

National Cancer Institute

\section{Source}

National Cancer Institute. Device Age. NCI Thesaurus. Code C93802.

A measure (or best estimate) of the length of time during which a device existed,

measured from manufacture date (and time) to a given date (and time) of use. 